\title{
Could mild hypoxia impair pilot decision making in emergencies?
}

\author{
Stephen Legg ${ }^{\mathrm{a} *}$, Stephen Hill ${ }^{\mathrm{b}}$, Toby Mundel ${ }^{\mathrm{c}}$, Andrew Gilbey ${ }^{\mathrm{d}}, \mathrm{Zac}_{\mathrm{Schlader}}^{\mathrm{c}}$ and Aaron Raman ${ }^{\mathrm{c}}$ \\ ${ }^{a}$ Centre for Ergonomics, Occupational Safety and Health, School of Management, College of Business, Palm- \\ erston North, New Zealand \\ ${ }^{b}$ School of Psychology, College of Humanities, Massey University, Private Bag 11222, Palmerston North, New \\ Zealand \\ ${ }^{c}$ School of Sport and Exercise, College of Sciences, Massey University, Private Bag 11222, Palmerston North, \\ New Zealand \\ ${ }^{d}$ School of Aviation, College of Business, Massey University, Private Bag 11222, Palmerston North, New Zealand
}

\begin{abstract}
The decreased pressure in the cabin of a pressurised aircraft (typically equivalent to $\sim 8000 \mathrm{ft}$ ) reduces the oxygen level so that the blood oxygen saturation of all occupants falls from $>97 \%$ (normoxia) at sea-level to below $92 \%$ (mild hypoxia). Although exposure to mild hypoxia does not affect well-learned cognitive and motor performance of aircrew, it has been proposed that it can affect the performance of some complex cognitive performance tasks involving multiple demands typical of emergency tasks that may have to be performed by pilots. In order to simulate some of these complex cognitive demands, 25 student volunteers participated in an experiment which assessed performance of complex logical reasoning and and multiple memory tasks before and after 2 hours of exposure to normoxia and mild hypoxia. Performance for the more difficult components of the complex reasoning task, especially involving conflict decisions, were marginally significantly degraded by mild hypoxia. Since the effects were only marginally significant future studies should investigate the effects of mild hypoxia on more subtle complex decision-making tasks.
\end{abstract}

Keywords: altitude, psychology, performance, aviation, decision-making, novel tasks

\section{Introduction}

Commercial and military aircrew (as well as passengers) are exposed to mild hypoxia during normal flights in pressurised aircraft. The decreased pressure in the aircraft cabin (equivalent to about $2438 \mathrm{~m} / 8000 \mathrm{ft}$ ) reduces the partial pressure of oxygen so that on a typical flight a person's arterial oxygen saturation is reduced from $>97 \%$ (normoxia, as at sea-level) to below $92 \%$. Previous laboratory studies have shown that exposure to this level of mild hypoxia does not affect well-learned cognitive, vigilance and perceptual-motor performance tasks [10, $12,15,16,22]$. However several early studies have reported equivocal findings for the effects of this level of mild hypoxia on complex, multiple, time shared tasks, or simulated flight activities [13, 14, 17]. In contrast, some of the early studies and also more recent studies have shown that this level of mild hypoxia can affect the performance of novel and complex cognitive tasks involving multiple demands $[1,3$, $9,11,12,18]$ including procedural errors in simulated flight [20]. These latter findings are consistent with real-world observations of acute symptoms of hypoxia at altitudes below $10,000 \mathrm{ft}$ in operational helicopter crew [23] and impaired sleep quality in laboratory studies at $9000 \mathrm{ft}[21]$ and in aircraft cabins at $2438 \mathrm{~m}$ (8000ft) [19]. Indeed, Denison et al. [3] reported that learning in complex tasks at altitudes as low as $1500 \mathrm{~m}(5000 \mathrm{ft})$ was slower than at sea level. The relevance of this latter finding for aviators was reinforced by in a 'review of mild hypoxia and the

\footnotetext{
* Corresponding author. E-mail: s.j.legg@massey.ac.nz
} 
use of oxygen in flight' by Ernsting [7]. More recently the saliency of these early findings were reinforced in a letter to the editor of this journal by Coote et al. [2], who pointed out that it would 'appear that at present cabin altitudes, though the routine cockpit tasks of pilots can be performed competently, the learning of a novel task is impaired'.

Although there appears to be increasing evidence for performance impairment for pilot tasks that are novel and complex at cabin altitudes of $2438 \mathrm{~m}$ $(8000 \mathrm{ft})$, there has been no change in the general aviation standard requirement for the use of supplementary oxygen only above a threshold of $10,000 \mathrm{ft}$. This could be construed as irresponsible if there were widespread agreement, based on evidence, that a lower threshold, such as $8000 \mathrm{ft}$ were more appropriate. There is therefore clearly a need for more discerning and well- controlled studies of the effects 'mild hypoxia' and specifically of the effects of exposure to a 'cabin' altitude equivalent to $2438 \mathrm{~m}$ $(8000 \mathrm{ft})$ on aspects of pilot performance that more closely reflect the underlying psychological components of complex and novel task performance.

The present study examined the effects of exposure to normobaric mild hypoxia (i.e. exposure to an altitude equivalent to $2438 \mathrm{~m}(8000 \mathrm{ft})$ ) on some psychological tests that we hypothesised were likely to be affected on account of their complexity and novelty. The tests were chosen because they were cognitively demanding, included aspects of novelty and conflict - and were basic cognitive capacities that are drawn on in a wide variety of real-world situations including aviation piloting procedures. Specifically, we examined the effects of mild hypoxia on complex logical reasoning and multiple memory.

\section{Methods}

25 male student volunteers were recruited for this study. This study protocol was approved by the Massey University Human Ethics Committee and was performed according to the Declaration of Helsinki. Each volunteer provided informed written consent prior to participating. The study involved a repeated measures design so females were excluded in order avoid potential confounding factors associated with menstrual cycle hormones.

This study employed a balanced cross-over design. All trials were separated by at least $24 \mathrm{~h}$. During the trials, subjects were exposed to either normobaric normoxia or normobaric mild hypoxia intended to mimic a 'cabin' altitude of $\sim 2438 \mathrm{~m}(8000 \mathrm{ft})$. This was accomplished by the subjects breathing via a mouthpiece, whilst wearing a noseclip, connected through a one-way valve (Hans Rudolf Inc. Kansas City, MO, USA, Model 1400) attached to a standard Douglas bag. The Douglas bag contained either a normoxic or a hypoxic gas mixture. The mild hypoxia gas mixture was accomplished by a hypoxicator device (Biomedtech Pty Ltd, Melbourne, Australia). The fraction of inspired oxygen $\left(\mathrm{FiO}_{2}\right)$ during the normoxia trials was $20.6 \pm 0.2 \%$, while the $\mathrm{FiO}_{2}$ during the mild hypoxia trials was $14.3 \pm 0.4 \%$. All trials were conducted in a moderate ambient environment $\left(20.6 \pm 1.4^{\circ} \mathrm{C}\right)$ at sea level. The barometric pressure during all trials was $756 \pm 6 \mathrm{mmHg}$.

Arterial oxygen saturation $\left(\mathrm{S}_{\mathrm{a}} \mathrm{O}_{2}\right)$ was estimated with a finger pulse oximeter (MD300K, Vacumed, Ventura, California). The amount of time in which a sustained reduction of each participant's $\mathrm{S}_{\mathrm{a}} \mathrm{O}_{2}$ was achieved was determined in a familiarization session in which it was found that it took $7 \pm 2 \mathrm{~min}$ for the normobaric mild hypoxia to reduce the subject's $\mathrm{S}_{\mathrm{a}} \mathrm{O}_{2}$ to $90 \pm 1 \%$. Heart rate (HR; Polar Vantage XL, Polar Electro, Kemple, Finland) and end-tidal $\mathrm{CO}_{2}$ $\left(\mathrm{P}_{\mathrm{ET}} \mathrm{CO}_{2} ; \mathrm{O}_{2} / \mathrm{CO}_{2}\right.$ Gas Analyzer, ADInstruments, Bellavista, NSW, Australia) were measured continuously.

The participants carried out 'blocks' of a complex logical reasoning task, a multiple memory task and a simple vigilance psychomotor task before (baseline) and after 30 and 90 minutes of exposure to each trial condition (normoxia or mild hypoxia). Self-perceived risk judgement was assessed immediately before the end of each trial exposure.

The complex logical reasoning was a belief bias task (after Evans [8] and De Neys [5]). It involved 12 blocks of logical syllogisms presented on a computer screen. Participants were required to determine whether each syllogism was valid or invalid by answering true or false. People find logical syllogisms difficult when believability of the conclusion conflicts with the validity of the argument. Unbelievable conclusions incline people to think that syllogisms are invalid. Believable conclusions incline people to think syllogisms are valid. This behaviour is known as belief bias. For example the syllogism: All mammals can walk. Whales are mammals. Whales can walk' provides a valid conclusion but since it is unbelievable, participants are more likely to indicate it is invalid. It is a conflict syllogism and therefore harder to get right. Belief bias makes judging the validity of conflict syllogisms hard and non-conflict syllogisms easy. Thus non-conflict valid (NV) syllogisms are 
considered to be 'easy', non-conflict invalid (NI) syllogisms are 'difficult', conflict valid (CV) syllogisms are 'fairly difficult' and conflict invalid (CI) syllogisms are 'the most difficult'.

Each block of syllogisms contained 6 conflict and 6 non-conflict syllogisms. Half were valid and half were invalid. The accuracy and response time (RT) for each syllogism were measured. In addition, a reasoning quality index (RQI) was obtained in the form of 'accuracy per 10 seconds of reasoning time' by dividing the accuracy of each item by how long it took to solve (the RT in milliseconds) and multiplying the outcome by 10,000 in order to generate values between 0 and 1 . Roughly speaking this provides a measure of 'proportion correct per 10 seconds.' For example a score of 0.04 would indicate an improvement in performance of $4 \%$. It should be noted that scores above 1 are possible when accuracy is high (90\% or more) and mean RT low (less than $10 \mathrm{sec}-$ onds) although these were rarely obtained. RQI provides a rough way of dealing with individual differences in speed/accuracy tradeoffs in the reasoning task.

The multiple memory task incorporated combined working memory (based on Daneman and Carpenter [4]) and prospective memory (based on Einstein et al [6]) tasks, presented in blocks. Each block contained 60 sentences divided up into 15 clusters, 3 each of sets of 2 - 6 sentences. Working memory included a processing component in which an error score for judgement of the semantic and/or syntactic sense of a sentence (the sentence error score - out of 60) was assessed (e.g. 'He was a fanatical yellow of football, rugby and cricket' does not make sense), and a memory component which was assessed as recall of the last word of each sentence set ('cricket' in the example) - a measure of modified reading span [4]. At the end of each block, participants were asked to recall the last word of each of the sentences in the block. The outcome measure was a working memory span score (i.e. correct recall out of 60). Additionally, 10 blocks contained a prospective memory trial in which participants had to indicate by pressing the letter ' $\mathrm{F}$ ' on the computer every time they detected the letters 'ean' in a word e.g. 'Everyone knew his distinctive purple beanie and shoes'. The outcome measure was another prospective memory score in the form of the proportion of items recalled correctly.

\subsection{Data analysis}

$\mathrm{HR}, \mathrm{P}_{\mathrm{ET}} \mathrm{CO}_{2}$ and $\mathrm{S}_{\mathrm{a}} \mathrm{O}_{2}$ were analyzed via a 2-way (trial $\mathrm{x}$ time) repeated measures analysis of variance (ANOVA). Data were assessed for approximation to a normal distribution and sphericity, and no corrections were necessary. When the two-way ANOVA revealed an $F$ test indicating a significant interaction or effect of time, post hoc pair-wise comparisons were made incorporating a Bonferroni adjustment. These data were analyzed using SPSS statistical software (V. 15, Chicago, IL, USA) with a priori statistical significance set at $\mathrm{P}<0.05$.

All of the complex logical reasoning and multiple memory task outcome measures were initially examined for normality (Shapiro-Wilks test). If normality was violated, no further analysis was conducted. For the outcome measures that were normally distributed the changes from each individual's baseline (normoxic) score were calculated as the dependent variable and examined using repeated measures 2[Oxygen Condition] x 2[Block] analyses of variance (ANOVA). The reasoning task analysis included an additional two factors: Conflict (nonconflict, conflict), and Validity (valid, invalid). Reduced performance was indicated by reductions in all outcome measures except for response times (i.e. logical reasoning response time), where a reduced performance was indicated by an increase in response time. Since the sample size was relatively small, effects were reported up to $\mathrm{p} \leq 0.10$.

\section{Results}

Baseline HR (mean \pm standard deviation) $(72 \pm 14$ bpm), $\mathrm{P}_{\mathrm{ET}} \mathrm{CO}_{2}(43 \pm 9 \mathrm{mmHg})$ and $\mathrm{S}_{\mathrm{a}} \mathrm{O}_{2}(97 \pm 1 \%)$, were similar $(p>0.05)$ between trials. HR decreased $(\mathrm{p}<0.001)$ similarly $(\mathrm{p}>0.05)$ over time in both trials by $5 \mathrm{bpm}$ (mean final HR: $67 \pm 11 \mathrm{bpm}$ ). However, $\mathrm{P}_{\mathrm{ET}} \mathrm{CO}_{2}$ was maintained similarly $(\mathrm{p}>0.05)$ both over time and between trials (mean: $43 \pm 9 \mathrm{mmHg}$ ). For normoxia, the mean $\mathrm{S}_{\mathrm{a}} \mathrm{O}_{2}(97 \pm 1 \%)$ was maintained $(\mathrm{p}>0.05)$ throughout the trial duration. For mild hypoxia, following the baseline measures $\mathrm{S}_{\mathrm{a}} \mathrm{O}_{2}$ was significantly reduced $(\mathrm{p}<0.001)$ to $91 \pm 2 \%$ and was sustained $(p>0.05)$ throughout the remainder of the trial.

Nearly all of the complex logical reasoning accuracy data violated normality (Shapiro-Wilks tests $\mathrm{p} \leq 0.01)$. Because violations were in opposing directions it was not possible to normalise the data with 
transformations. Therefore the accuracy data could not be analysed by ANOVA. Most of the reasoning response time data and the composite RQI variables were normally distributed (although a few were non-

Table 1

Effects of exposure to normoxia and mild hypoxia on complex logical reasoning and multiple memory tasks (see methods for details of measurements). Mean (SD) data $(\mathrm{n}=25)$ is shown for baseline and after 30 and 90 minutes of 2 hour exposures

\begin{tabular}{|c|c|c|c|c|c|c|}
\hline & \multicolumn{3}{|l|}{ Normoxia } & \multicolumn{3}{|c|}{ Mild Hypoxia } \\
\hline & Baseline & $\begin{array}{l}\text { After } 30 \\
\text { minutes }\end{array}$ & $\begin{array}{l}\text { After } 90 \\
\text { minutes }\end{array}$ & $\begin{array}{l}\text { Baseline } \\
\text { (normoxia) }\end{array}$ & $\begin{array}{l}\text { After } 30 \\
\text { minutes }\end{array}$ & $\begin{array}{l}\text { After } 90 \\
\text { minutes }\end{array}$ \\
\hline \multicolumn{7}{|l|}{ Complex logical reasoning task } \\
\hline \multicolumn{7}{|l|}{ Accuracy (proportion correct) } \\
\hline Non conflict Valid syllogisms & $\begin{array}{l}0.89 \\
(0.19)\end{array}$ & $\begin{array}{l}0.88 \\
(0.16)\end{array}$ & $\begin{array}{l}0.88 \\
(0.19)\end{array}$ & $\begin{array}{l}0.85 \\
(0.24)\end{array}$ & $\begin{array}{l}0.83 \\
(0.24)\end{array}$ & $\begin{array}{l}0.88 \\
(0.21)\end{array}$ \\
\hline Non conflict Invalid syllogisms & $\begin{array}{l}0.75 \\
(0.28)\end{array}$ & $\begin{array}{l}0.60 \\
(0.32)\end{array}$ & $\begin{array}{l}0.64 \\
(0.32)\end{array}$ & $\begin{array}{l}0.68 \\
(0.35)\end{array}$ & $\begin{array}{l}0.64 \\
(0.30)\end{array}$ & $\begin{array}{l}0.67 \\
(0.32)\end{array}$ \\
\hline Conflict Valid syllogisms & $\begin{array}{l}0.73 \\
(0.24)\end{array}$ & $\begin{array}{l}0.77 \\
(0.23)\end{array}$ & $\begin{array}{l}0.77 \\
(0.25)\end{array}$ & $\begin{array}{l}0.75 \\
(0.24)\end{array}$ & $\begin{array}{l}0.79 \\
(0.25)\end{array}$ & $\begin{array}{l}0.76 \\
(0.31)\end{array}$ \\
\hline Conflict Invalid syllogisms & $\begin{array}{l}0.40 \\
(0.35)\end{array}$ & $\begin{array}{l}0.53 \\
(0.36)\end{array}$ & $\begin{array}{l}0.63 \\
(0.32)\end{array}$ & $\begin{array}{l}0.43 \\
(0.34)\end{array}$ & $\begin{array}{l}0.57 \\
(0.31)\end{array}$ & $\begin{array}{l}0.56 \\
(0.37)\end{array}$ \\
\hline \multicolumn{7}{|l|}{ Response time (msec) } \\
\hline Non conflict Valid syllogisms & $\begin{array}{l}12285 \\
(4843)\end{array}$ & $\begin{array}{l}12221 \\
(5099)\end{array}$ & $\begin{array}{l}11262 \\
(4052)\end{array}$ & $\begin{array}{l}12799 \\
(6495)\end{array}$ & $\begin{array}{l}11950 \\
(5512)\end{array}$ & $\begin{array}{l}10727 \\
(4047)\end{array}$ \\
\hline Non conflict Invalid syllogisms & $\begin{array}{l}17076 \\
(8011)\end{array}$ & $\begin{array}{l}14087 \\
(6673)\end{array}$ & $\begin{array}{l}12573 \\
(4797)\end{array}$ & $\begin{array}{l}15251 \\
(6699)\end{array}$ & $\begin{array}{l}14265 \\
(7436)\end{array}$ & $\begin{array}{l}12528 \\
(6093)\end{array}$ \\
\hline Conflict Valid syllogisms & $\begin{array}{l}12034 \\
(5066)\end{array}$ & $\begin{array}{l}13303 \\
(4352)\end{array}$ & $\begin{array}{l}10006 \\
(2813)\end{array}$ & $\begin{array}{l}13102 \\
(8238)\end{array}$ & $\begin{array}{l}12363 \\
(5302)\end{array}$ & $\begin{array}{l}12595 \\
(5318)\end{array}$ \\
\hline Conflict Invalid syllogisms & $\begin{array}{l}16541 \\
(6663)\end{array}$ & $\begin{array}{l}11631 \\
(4233)\end{array}$ & $\begin{array}{l}11138 \\
(4043)\end{array}$ & $\begin{array}{l}16133 \\
(9706)\end{array}$ & $\begin{array}{l}13497 \\
(7537)\end{array}$ & $\begin{array}{l}11889 \\
(4921)\end{array}$ \\
\hline \multicolumn{7}{|c|}{ Reasoning quality index (accuracy/response time $\mathrm{x} 10,000)$} \\
\hline Non conflict Valid syllogisms & $\begin{array}{l}0.85 \\
(0.39)\end{array}$ & $\begin{array}{l}0.85 \\
(0.39)\end{array}$ & $\begin{array}{l}0.88 \\
(0.34)\end{array}$ & $\begin{array}{l}0.82 \\
(0.46)\end{array}$ & $\begin{array}{l}0.84 \\
(0.47)\end{array}$ & $\begin{array}{l}0.96 \\
(0.48)\end{array}$ \\
\hline Non conflict Invalid syllogisms & $\begin{array}{l}0.55 \\
(0.32)\end{array}$ & $\begin{array}{l}0.56 \\
(0.41)\end{array}$ & $\begin{array}{l}0.58 \\
(0.42)\end{array}$ & $\begin{array}{l}0.57 \\
(0.45)\end{array}$ & $\begin{array}{l}0.51 \\
(0.31)\end{array}$ & $\begin{array}{l}0.59 \\
(0.31)\end{array}$ \\
\hline Conflict Valid syllogisms & $\begin{array}{l}0.73 \\
(0.44)\end{array}$ & $\begin{array}{l}0.64 \\
(0.28)\end{array}$ & $\begin{array}{l}0.83 \\
(0.36)\end{array}$ & $\begin{array}{l}0.78 \\
(0.48)\end{array}$ & $\begin{array}{l}0.74 \\
(0.40)\end{array}$ & $\begin{array}{l}0.74 \\
(0.50)\end{array}$ \\
\hline Conflict Invalid syllogisms & $\begin{array}{l}0.24 \\
(0.20)\end{array}$ & $\begin{array}{l}0.49 \\
(0.38)\end{array}$ & $\begin{array}{l}0.63 \\
(0.36)\end{array}$ & $\begin{array}{l}0.31 \\
(0.31)\end{array}$ & $\begin{array}{l}0.46 \\
(0.25)\end{array}$ & $\begin{array}{l}0.52 \\
(0.40)\end{array}$ \\
\hline \multicolumn{7}{|l|}{ Multiple memory task } \\
\hline $\begin{array}{l}\text { Sentence error score } \\
\text { (out of } 60 \text { ) }\end{array}$ & $\begin{array}{l}4.8 \\
(3.6)\end{array}$ & $\begin{array}{l}4.0 \\
(3.0)\end{array}$ & $\begin{array}{l}6.1 \\
(4.2)\end{array}$ & $\begin{array}{l}5.4 \\
(3.0)\end{array}$ & $\begin{array}{l}5.0 \\
(3.9)\end{array}$ & $\begin{array}{l}5.9 \\
(4.1)\end{array}$ \\
\hline $\begin{array}{l}\text { Working memory span score } \\
\text { (recall out of } 60 \text { ) }\end{array}$ & $\begin{array}{l}40.7 \\
(11.4)\end{array}$ & $\begin{array}{l}42.7 \\
(10.0)\end{array}$ & $\begin{array}{l}42.8 \\
(10.8)\end{array}$ & $\begin{array}{l}41.5 \\
(10.4)\end{array}$ & $\begin{array}{l}44.1 \\
(11.3)\end{array}$ & $\begin{array}{l}44.5 \\
(11.2)\end{array}$ \\
\hline $\begin{array}{l}\text { Prospective memory score } \\
\text { (proportion of items correct) }\end{array}$ & $\begin{array}{l}0.23 \\
(0.24)\end{array}$ & $\begin{array}{l}0.22 \\
(0.27)\end{array}$ & $\begin{array}{l}0.19 \\
(0.25)\end{array}$ & $\begin{array}{l}0.30 \\
(0.31)\end{array}$ & $\begin{array}{l}0.32 \\
(0.34)\end{array}$ & $\begin{array}{l}0.25 \\
(0.24)\end{array}$ \\
\hline
\end{tabular}

normal), so it was possible to perform ANOVAs on these data. Table 1 shows the data for the complex logical reasoning and multiple memory tasks.

Complex logical reasoning response time performance was marginally significantly poorer under mild hypoxia for invalid ('difficult') items but not for valid ('easy') items [Validity x Oxygen Condition interaction $[\mathrm{F}(1,24)=3.14, \mathrm{p}=0.089$, Wilks' Lambda $=$ 0.884 ] and there was marginally significant improvement in response time performance for valid ('easy') items under hypoxia at 30 minutes but not at 90 minutes [Validity x Oxygen Condition x Block interaction $(\mathrm{F}(1,24)=2.98, \mathrm{p}=0.097$, Wilks' Lambda $=0.890]$.

There was also a marginally significant Conflict $\mathrm{x}$ Validity x Oxygen Condition x Block interaction [F(1, $24)=3.74, p=0.065$, Wilks' Lambda $=0.865]$. The easiest way to understand this interaction is to describe the patterns of performance across the four types of syllogism. Non-conflict valid (NV, easy) syllogisms showed an improvement in response performance from $30 \mathrm{~min}$ to $90 \mathrm{~min}$ under both oxygen conditions. However, the improvement was greater for mild hypoxia. Non-conflict invalid (NI, difficult) syllogisms also showed an improvement in response 
performance from $30 \mathrm{~min}$ to $90 \mathrm{~min}$ under both normoxic and hypoxic conditions. However, the effect was the opposite of that found for NV syllogisms with the improvement being larger under normoxic conditions. Conflict valid (CV, fairly difficult) syllogisms showed a slightly greater improvement under hypoxia at 30 minutes and greater improvement under normoxia at 90 minutes. Conflict invalid (CI, the most difficult) syllogisms exhibited a similar pattern to that for NI syllogisms. In summary this marginally significant interaction indicated that response time performance tended to be poorer for mild hypoxia for difficult syllogisms, especially after the longer (90 minute) exposure. However, caution must be taken in interpreting these results because poorer response time performance does not necessarily mean a better overall performance (i.e. more accurate responding).

The RQI analysis provides a better sense of the ways in which the combination of accuracy and response time is affected by mild hypoxia. There was a marginally significant Conflict $\mathrm{x}$ Oxygen Condition $\mathrm{x}$ Block interaction $(\mathrm{F}(1,24)=3.83, \mathrm{p}=0.062$, Wilks' Lambda $=0.862$ ). Thus the main finding for RQI was that there were smaller increases in performance for Conflict ('difficult') syllogisms (particularly the CI syllogisms) under hypoxia at 90 minutes than under normoxia. By contrast the easier nonconflict syllogisms were either no worse under mild hypoxia than normoxia or (perhaps) slightly better. These findings are consistent with the hypothesis that hypoxia affects difficult reasoning syllogisms but not easier ones, especially after a longer exposure. On closer inspection of the raw data, it was found that accuracy approached ceiling for some of the syllogisms, particularly the easier ones, so that any increase in performance from baseline for these could not be large. This acted to 'artificially suppress'the magnitude of changes for some of the easier syllogisms. This effectively made the findings relatively conservative. It therefore provided additional strength for the finding that performance for difficult syllogisms tended to be reduced by mild hypoxia.

In the multiple memory task, a marginally significant interaction for Oxygen Condition and Block $(\mathrm{F}(1$, 24) $=3.65, \mathrm{p}=0.068$, Wilks' Lambda $=0.868$ indicated that relative to baseline, sentence error scores were poorer for mild hypoxia after 30 min but greater for normoxia after $90 \mathrm{~min}$. This was indicative of a poorer performance for mild hypoxia after $30 \mathrm{~min}$ and after $90 \mathrm{~min}$ for normoxia. In contrast performance for working memory span at 30 minutes was a marginally significantly better for mild hypoxia than normoxia but the effect reversed at 90 minutes [Oxygen Condition and Block $(\mathrm{F}(1,24)=3.00$, $\mathrm{p}=0.096$, Wilks' Lambda $=0.889)$. There were no significant effects of Oxygen Condition on performance of the prospective memory score. In summary, mild hypoxia did not appear to impair performance on the multiple memory task.

\section{Discussion}

The main finding of this study was that exposure to acute (two hours) of normobaric mild hypoxia did not significantly affect performance for complex logical reasoning and multiple memory tasks in 25 students. However performance for the difficult (i.e. conflict) and most difficult (i.e. the conflict invalid) syllogisms were consistently marginally significantly poorer for mild hypoxia. This finding is consistent with the view that the more complex (conflict and novel) aspects of decision-making may be impaired by exposure to mild hypoxia. It would also explain why the memory tasks were unaffected by mild hypoxia in this study, since they were far less complex and novel and did not include conflict.

Although the present study, like many previous similar studies, has failed to demonstrate a clear effect of mild hypoxia on complex decision-making, the results provide sufficiently encouraging evidence to warrant further study. In particular, we believe that future studies should be extended to include multiple levels (e.g. 6, 8, 10, 12 and 14, $000 \mathrm{ft}$ ) of hypobaric hypoxia (i.e. be conducted in a hypobaric chamber) and more discerning tests of complex reasoning/decision-making which include aspects of novelty and conflict decision making. This is easier said than done. We suggest that future studies should include a range of tests that tax participants' performance in areas such as executive, innovative, creative and flexible thinking, typical of that required in crisis or emergency management. Some of the behaviours that characterise this type of thinking include: dealing with all kinds of novelty; comprehending and coping with a rapidly changing situation; keeping track of events and remembering the 'big picture'( situational awareness); complex multitasking; decisions about when to ignore irrelevant information; changing plans following receipt of new information; producing innovative solutions to problems; assessing risks and anticipating the range of consequences of an action; showing insight into ones performance; communicating effectively; behaviour control (avoiding irritable 
outbursts), and: empathy with other people (detecting subtleties in their behaviour). In addition, in order to more closely examine the effects of real-world exposures, future studies should examine the combined effects of mild hypoxia with dehydration, sleep loss, long continuous working hours and circadian dysrhythmia, all of which are common in aviation.

\section{Conclusions}

The present study showed that exposure to mild hypoxia (equivalent to $8000 \mathrm{ft}$ altitude) did not significantly impair complex decision-making and multiple memory performance in 25 students but suggested that very difficult conflict complex reasoning may be impaired.

\section{Acknowledgement}

This study was supported by Massey University Research Fund and the New Zealand Defence Force Defence Technology Agency.

\section{References}

[1] Crow T.J. and Kelman G.R. (1969). Physiological effects of mild hypoxia. J Physiol. 204, 24.

[2] Coote JH, Nicholson AN and Spencer MB, Sleep and Performance at Cabin Altitudes (2010). Aviation, Space, and Environmental Medicine 81 (2), 149.

[3] Denison, D.M., Ledwith, F., Poulton, E.C. (1966). Complex reaction times at simulated cabin altitudes of 5000 feet and 8000 feet. Aerospace Medicine, 37: 1010-3.

[4] Daneman, M., \& Carpenter, P. A. (1980). Individual differences in working memory and reading. Journal of Verbal Learning and Verbal Behavior, 19, 450-466.

[5] De Neys, W. (2006). Dual processing in reasoning: Two systems but one reasoner. Psychological Science, 17, 428-433.

[6] Einstein, G. O., McDaniel, M. A., Thomas, R., Mayfield, S., Shank, H., Morrisette, N., et al. (2005). Multiple processes in prospective memory retrieval: Factors determining monitoring versus spontaneous retrieval. Journal of Experimental Psychology: General, 134, 327-342.

[7] Ernsting (1984). Mild hypoxia and the use of oxygen in flight. Aviation, Space and Environmental Medicine 55:407410.

[8] Evans, J.S.B.T. (2003). In two minds: Dual process accounts of reasoning. Trends in Cognitive Sciences, 10, 454459.

[9] Farmer, E.W., Lupa, H.T., Dunlop, F. and McGowan, J.F., (1992). Task learning under mild hypoxia. In: Sutton, J.R., Coates, G. And Houston, C.S. (eds). Hypoxia and mountain medicine. Advances in the biosciences. Burlington, VT: Queen City Printers;1-8.
[10] Fiorica, V., Burr, M.J. and Moses, R. (1971). Effects of low grade hypoxia on performance in a vigilance situation. Office of Aviation Medicine, Federal Aviation Administration Technical Report FAA-AM-71-11, March, 1-9.

[11] Fowler, B., Elcombe, D., Kelso, B. and Porlier, G., (1987). The threshold for hypoxia effects on perceptualmotor performance. Human Factors, 29 (1), 61-66.

[12] Fowler, B., Paul, M., Porlier, G., Elcombe, D.D. and Taylor, M., (1985). A re-evaluation of the minimum altitude at which hypoxic performance decrements can be detected. Ergonomics, 28, 781-791.

[13] Frisby, J.P., Barrett, R.F. and Thornton, J.A., (1973). Effect of mild acute hypoxia on a decision-making task. Aerospace Medicine, 44, 523-526.

[14] Gold, R.E. and Kulak, L.L., (1972). Effects of hypoxia on aircraft pilot performance. Aerospace Medicine, 43, 180 183.

[15] Green, R.G. and Morgan, D.R. (1985). The effects of mild hypoxia on a logical reasoning task. Aviation Space and Environmental Medicine, 56 (10), 1004-8.

[16] Hewett, K.J., Curry, I. P., Rath, E. and Collins, S.M., (2009). Subtle cognitive effects of moderate hypoxia. United States Army Aeromedical Research Laboratory (USAARL) Report No. 2009-17.

[17] Ledwith, F. and Denison, D.M., (1964). Complex reaction times at a simulated cabin altitude of 8000 feet. RAF Institute of Aviation Medicine Report No 284, Farnborough, Hants, UK.

[18] McCarthy, D., Corban, R., Legg, S. and Faris, J. (1995). Effects of mild hypoxia on perceptual-motor performance: a signal detection approach. Ergonomics, 38 (10), 1979-92.

[19] Muhn, J.M., Signal, T.M., Rock, P.B, Jones, S.P, O'Keefe, K.M, Weaver, M.R, Zhu, S, Gander, P.H. and Belenky, G. (2009). Sleep at silulated $2438 \mathrm{~m}$ : effects on oxygenation, sleep quality, and post sleep performance. Aviation Space and Environmental Medicine, 80 98), 691-7.

[20] Nesthus, T.E., Rush, L.1. and Wreggit, S.S., (1997). Effects of mild hypoxia on pilot performances it general aviation altitudes. US Department of Transportation, Civil Aeromedical Institute, Federal Aviation Administration Report DOT/FAA/AM-97/9. Available through the National Technical Information Service, Springfield, Virginia 22161.

[21] Nicholson AN, Smith PA, Stone BM, Bradwell AR and Coote JH. (1988). Altitude insomnia during an expedition to the Himalayas. Sleep 11, 354-61.

[22] Paul, M. A. and Fraser, W. D. (1994). Performance during mild acute hypoxia. Aviation Space and Environmental Medicine, 65 (10 Pt 1), 891-9.

[23] Smith, A. (2005). Hypoxia symptoms reported during helicopter operations below 10,000 ft: a retrospective survey. Aviation Space and Environmental Medicine, 76 (8), 94-8. 